\title{
Research on the Innovation of Social Management in the New Media Era
}

\author{
Xuemei Dai ${ }^{1,2}$, Jinyong $\mathrm{Li}^{3,}$ * \\ ${ }^{1}$ Department of Marxism, Xi`an University of Science and Technology, Shaanxi, Xi'an 710000, China; \\ ${ }^{2}$ English Department, Hanjiang Normal University, Hubei, Shiyan, 442000, China \\ ${ }^{3}$ Department of Marxism, Xi'an University of Science and Technology, Shaanxi, Xi'an 710000, China \\ paperiset@163.com \\ *Correspondence author: Jinyong Li
}

Keywords: Growth and development, China's youth, Internet to manage social change, Present situation

\begin{abstract}
This paper explores the relationship between the Chinese Government, new social policy, the Internet and youth development. The implementation of the 'Harmonious society' indicates that the government is moving from a directive, top-down approach to managing social and youth development and towards a more consultative, interactive style using the Internet as a new medium to access and respond to cultural ruptures in the fabric of Chinese society. The paper draws on the emerging genre of grunge and shock' literature and illustrates the types of cultural ruptures that raise concern among authorities in relation to the direction of youth development. Responding to the change, the government has began to utilize key characteristics of the Internet to efficiently consult and interact with youth linking into the popularity of this controlled new media technology as a way to access this diverse social grouping and provide immediate information on emerging social, and potentially destabilizing issues. The result is that the government is potentially more responsive to emerging youth issues relating to structures, values and roles in China's rapidly changing social milieu.
\end{abstract}

\section{Introduction}

As China pushes ahead with economic reforms and continues to manage social change, the task of defining what it means to be a young person in China is taking on a new urgency. Over half the population, or more than 630 million youth, are between 18 to 35 years and their impact on economic and social development of China over the next 20 years cannot be overstated. Yet, this age grouping does not adequately describe what is far from a homogenous populace. There exist a number of the political, economic, social, cultural and technological forces that militate against the smooth implementation of gradual social change in Chinese society. These include leadership transition and its impact (e.g. third to fourth generation and policy implementation of the Harmonious Society Theory) [1]; political inefficiencies (e.g. Communist Party relevancy and corruption); unfinished economic reforms (e.g. WTO agreement implementation): technological advancement and regulation (i.e. new media technologies and convergence, including the Internet), and social problems (e.g. unemployment, a growing disparity between rural and urban living and a increasing diversity within the cohort of urban youth in terms of age, expectations, needs. education. income, career and wealth). This article focuses on the growing disparity between urban youth cohorts as a major concern for government authorities because it is these dynamics that add complexity to designing and integrating social change and development programs cohesively into the new economic fabric of Chinese society to benefit all stakeholders [2].

While promises of material gain and greater freedom have never been fully realized, the security associated with the Maoist system has disappeared. The second cohort, knowing only the materialism of the 1990s, have begun to establish their presence as they search for functional cultural identities in 
China's rapidly changing social structure [3]. Today, these youth experience a peculiar form of impotence associated with a 'one country two systems' policy with young people's willingness to push the parameters of "acceptable" behavior and the accompanying guilt (and retribution) when they do. As a result, youth have no clear model to follow with the Government encouraging them to be individualistic in some aspects (entrepreneurial and competitive) but not others (self-expression and empowerment) [4]. These aspects highlight how Chinese youth live their lives somewhere in between, precariously at times and brashly at others, feeling their way towards a functional coexistence of individualistic and collectivist value systems. When people do find an avenue to be heard, the Government often sees such manifestations (protests, collective actions and criticisms)' as cultural ruptures that break down the social cohesion of China and adversely affect its smooth transition to a market economy with Chinese characteristics. Recent tangible evidence of these ruptures (and government measures to address them) can be found in new commercial writing genres of "grange and shock” literature, which has gained popularity among China's youth counterculture.

The Government's response to the new demands of, and on, youth in modern China has been slow and cumbersome. Spiritual culture initiative emphasized a return to Confucian values to counter the negative influence of western ideas and thinking on the older cohort of youth and to protect the new cohort. However, the "spiritual culture" initiative remained an ambiguous concept that embodied a multiplicity of meanings and forged within a loose set of government regulations and practices. The Government's latest policy development of the Harmonious Society Theory continues to embrace central configurations of the old "spiritual culture" initiative (i.e. morality and advanced culture), but two changes mark significant shifts in the platform of youth development-technological advances and the study of youth.

\section{Social Change, Technology and Youth}

Throughout recent Chinese history, the task of educating the young is approached with great caution and is patterned and planned after the ideal culture of Chinese society. This means that the parameters of acceptable behavior were clearly delineated and social assumptions and beliefs were interwoven tightly into a cogent set of normative guidelines supporting the moral and political order. Responding to increasing tensions over the influence of western ideas, thinking and values, the Chinese Government implemented a range of strategies throughout the 1980s. It initiated corrective strategies in 1983 (the campaign against 'spiritual pollution') and again in 1987. Yet, much of the focus for youth remained on economic reform and the flow-on effect relating to potential prosperity, wealth and freedom. Youth responded in different ways as they traversed the uncertain social and cultural territories the new economic system ushered into China. Youth culture selectively adopted and internalized utopian socialist ideology, the advertised official ideology and the lived culture of the time. Resulting from this fusion of values systems were youth orientations that set them apart from previous generations who followed the directive of the Communist Party.

Television's role in this process of spiritual culture was crucial in promoting the new ethical and moral spirit, which is conducive to promoting the Government's vision of a socialist commodity economy. This is not to suggest the Chinese Government shuns western culture completely. In fact, it sees key aspects of western culture providing important mechanisms to promote economic reforms. Television drama has been called to the cause of constructing civic consciousness as well as instructing people in the modern ways of commerce and fair exchange. The private materialistic virtues of the 1990s are therefore to be counterbalanced by socialist ethics. This kind of double-checking mechanism is supposedly to assure that the spiritual mix is appropriate to propel the vehicle of reform. The problem for China's propagandists in the reform era has been to strike a balance between discourses of collectivism and individualism with the former being called upon to mould the moral subject, the latter to address the economic subject, the active consumer.

As a result of this ongoing dialogue between the two value systems throughout the late 1990s, official discourse and policy rendered Chinese modernity in terms of blending capitalism with race and Chinese tradition. Thus, the process of Chinese modernization links into strategies where the uniqueness of the Chinese race is continually evoked, together with the success of overseas Chinese 
communities as a way to exhort Chinese citizens to constantly improve their economic performance and, thus, strengthen the Chinese economy. Ironically, though, Jiang's focus on literature has not produced the same successes found in television as a mechanism to power the vehicle of spiritual culture and economic reform. China's flourishing market economy, which has promoted a range of individualistic values in youth, began to show major influences in China's contemporary literature. Young writers, publishers and government authorities battled from 1998 to the present over the appropriateness of changing values and cultural symbols and the dramatic change enveloping China's new literary industry. Each stakeholder simultaneously attempted to direct, control, change and assimilate new cultural representations and rebel against them. Resulting from this changing and conflicting social environment is a momentum of what it means to modern and young in Chinese society.

\section{Youth Development and the Internet}

Six key characteristics of the Internet--accessibility, efficiency, interactivity, popularity, immediacy and controllability-enhance the potential to successfully implement the Government's social change initiatives in relation to youth. Since 1997, the Internet has become a key technology with the Government promoting its expansion as critical to China becoming an economically advanced and politically powerful nation on a global scale. However, authorities also recognize the potential of the Internet to become a destabilizing force if unregulated. As a result, the Government implemented a raft of Internet policies from October 2010 and throughout 2011 to regulate service and content provision to bring its management under the umbrella of the highly regulated media. Much of the urgency behind implementing these regulations, designed to protect political and social stability and national security, was the unprecedented expansion and popularity of the Internet, particularly among China's youth. At a user level, Internet development has seen expediential growth in subscriber numbers from 2007 through to 2014. The number of Internet subscribers saw significant increases with figures doubling in each of the three surveyed periods. Overall, the growth for the 18 months exceeded $400 \%$. However, the flurry of activity in subscriber numbers slowed considerably during the surveyed period of the October 2010 policy launch on the Internet and the six-month period immediately following the announcement.

More importantly, though, is how youth have embraced this new information and communication medium. Overall, the highest user group is the $18-24$ year olds with $37.2 \%$. However, youth in general (15-35 year olds) dominate the users of the Internet (82\%) (CINNIC, 2012, pp. 7). The survey also reveals that the majority of users were highly educated with high school (30.5\%), college (26.3\%) and undergraduate (29.2\%) qualifications dominating the user profile. The three primary goals for accessing the Internet are to get information (47.6\%), entertainment (18.9\%) and making friends (14.9\%). Services most frequently used by youth include email (92.9\%), search engine (63.8\%), software downloading (51\%),online chat (45.5\%), information acquisition (40.3\%) and BBS/community forum (18.9\%) (CINNIC, 2013).

As a result of the growth and popularity of the Internet, enterprises and individual entrepreneurs have embraced the potential of China's Internet development (Sheff, 2012). For example, Jerry Yang of Yahoo, sohu.com founder Charles Zhang, and Net ease's William Ding became entrepreneurial icons of the youth generation. Embracing this entrepreneurial spirit, youth have added Internet companies to their preferred job list of working for multi-national or joint venture companies. By the beginning of 2010, young entrepreneurs flooded the market with an estimated 15,000 Internet start-ups. Given the trends associated with Internet policy development and diffusion and adoption rates, this new media technology has the potential to become a powerful mechanism to connect the Government to youth in more interactive ways. Two examples illustrate this potentiality. An Internet survey by the People's Daily was launched to gauge the nation's mood' on current issues affecting their lives. The survey was the first collaboration between the domestic politics department of the People's Daily and its online edition www.people.com.cn. It found that the top two issues related to the corruption and the impact of the WTO membership on China. The editor of the online newspaper suggests that the survey revealed that the ordinary people are really paying attention to corruption 
(Hsieh, 2012, p.7). A second newspaper China Daily and its online edition http://www.chinadaily.com.cn/news/index.html provide a web-based forum for Chinese citizenry to comment on various issues. For example, the website asks: When the 18th Communist Party of China (CPC) National Congress was held. Under the leadership of the CPC, the Chinese economy has flourished and people's lives have improved. What is your opinion on the future of the vast country? Within a two-week period, 59 postings were uploaded with $68 \%$ coming from China-based email addresses.

In both situations, the Government's use of the Internet to link to Chinese citizenry says more about its new consultative approach to social development than the findings or the comments themselves. Furthermore, both the survey and forum project the image of a more relevant, modern, open and participatory-oriented government organ that is willing to listen to the voices of Chinese citizens. This strategy illustrates attempts by the Government to utilize the characteristics of the Internet to society engage in a more consultative-interactive approach to social development by linking into the popularity of the Internet among youth as a way to access information and provide immediate information on (and responses to) youth structures, values and roles. However, the use of community forums or BBS (18.9\%) rates low in the services most frequently accessed by Chinese Internet users. More importantly, though, the success of using the Internet for social development is mitigated by government efforts to control the Internet. The blocking of the popular Google website in September 2012 limits Internet users in two key areas in relation to the 'primary goal for accessing' the Internet (getting information-47.6\%) and 'services most frequently used' (search engine-63.8\%). Further to this strategy is the integration of the Internet into the new digital infrastructure. If achieved, the Government will increase its control over the points of distribution (supplier) and consumption (user) under the pretence of providing a high-speed, interactive technology that offers newly expanded and essential consumer information and communication services within an e-commerce-government framework.

\section{Conclusions}

Discussion on the Government's development of the Internet has highlighted how the Internet can he potentially utilized for future social change as part of the Harmony Society initiative to focus new media technology on youth development. However, it is the underlying message a more consultative, interactive approach by the Government communicates to Chinese citizenry that may make the most impact on how successful social development legacy is viewed in the future. Given focus on making the Party more relevant through its 'pay attention to politics, use of the Internet as an interactive media projects an image of the Party nurturing a more open, receptive political style that caters for modern social developments. It also infers that Chinese youth can actively participate in the processes of government relating to issues affecting their lives. However, the Government's use of the Internet in a consultative way for youth development will not be gauged by whether the Party can access relevant and beneficial information on youth structures, values and roles. Instead, it will be assessed by youth on the speed and relevancy of the resulting social change and how they interpret the Government's monitoring, controlling and limiting of access to services popular among this important social group. Given recent efforts by the Government to control Internet services and content (regulation) and delivery methods (digital infrastructure), the strategy derides against its projected image of nurturing a more consultative approach to youth development.

\section{References}

[1] Dong Manyuan, Reform and Opening-up Bolstering China’s Hard and Soft Powers. China International Studies, 2008(04)

[2] Pei Yuanying. China's Diplomatic Strategy and Peaceful Development: Opportunities and Challenges. China International Studies, 2006(01)

[3] Li Jie, Soft Power Building and China’s Peaceful Development. China International Studies, 
2006(04)

[4] Xu Jian, Theoretical Reflections on Building a Harmonious World. China International Studies, 2007(01) 